\title{
PENERAPAN WEB SERVICE PADA SISTEM KEAMANAN PERKANTORAN MENGGUNAKAN ANDROID
}

\author{
Iwan Fitriady Mukhlis \\ STMIK Indonesia Banjarmasin \\ Jl Pangeran Hidayattullah samping jembatan Banua anyar Banjarmasin \\ e-mail:iwanfm2000@gmail.com
}

\begin{abstract}
Abstrak
Keamanan adalah keadaan bebas dari bahaya. Istilah ini bisa digunakan dengan hubungan kepada kejahatan, segala bentuk kecelakaan, dan lain-lain .Perkantoran adalah sebuah ruangan atau bangunan tempat runtuhan kegiatan tatausaha terlaksana untuk memuai, membenahi, mengembangkan dan mengawasi kegiatan usaha

Munculnyaberbagaimacamaplikasimemberikanpilihandalampeningkatankerjasuatu pekerjaan, baik yang bersifat desktop based, web based hingga yang sekarang inimunculnya aplikasi-aplikasi baru yang berjalandalam mobile seperti pada sistem platfrom android. Pada penelitan ini telah mengobservasi kebutuhan keamanan di sektor perkantoran. Pada sektor perkantoran ini banyak sekali permintaan pelayanan keamanan serta jasa lainnya yang diajukan oleh para penghuni kantor kepada pihak pengurus kantor sehingga faktor ini lah yang menjadi alasan pengembangan aplikasi yang lebihcanggih

Ditambah dengan adanya kendala dalam merespon kebutuhan para penghuni kantor dalam menanggapi setiap laporan tergolong lambat karena tidak adanya sistem yang mengakomodasi sistem ini.
\end{abstract}

Kata kunci: Keamanan, Sistem Keamanan, Web Service, Android.

\section{Abstract}

Security is a state of freedom from danger. This term can be used in connection with crime, all forms of accidents, etc. An office is a room or building where the ruins of administrative activities are carried out to expand, fix, develop and supervise business activities.

The emergence of various kinds of applications provides options in improving the work of a job, both desktopbased, web-based, until now the emergence of new applications running on mobile such as the android platform system. This research has observed the need for security in the office sector. In this office sector there are lots of requests for security services and other services submitted by office residents to office administrators so that this factor is the reason for developing more sophisticated applications.

Coupled with the constraints in responding to the needs of office residents in responding to each report is classified as slow because there is no system that accommodates this system.

Keywords: Security, Security System, Web Service, Android.

\section{PENDAHULUAN}

Pada penelitan ini telah mengobservasi kebutuhan keamanan di sektor perkantoran. Pada sektor perkantoran ini banyak sekali permintaan pelayanan keamanan serta jasa lainnya yang diajukan oleh para penghuni kantor kepada pihak pengurus perkantoran sehingga faktor ini lah yang menjadi alasan pengembangan aplikasi yang lebih canggih. Ditambah dengan adanya kendala dalam merespon kebutuhan para penghuni kantor dalam menaggapi setiap laporan tergolong lambat karena tidak adanya sistem yang mengakomodasi sistem ini.

Sistem Keamanan digunakan untuk memberikan rasa bebas dari bahaya, tidak merasa takut, resah, atau gelisah terhadap barang berharga yang ditinggalkan.sistem keamanan dapat mengetahui kemungkinan terjadinya pencurian terhadap barang berharga. Kantor adalah bangunan yang berfungsi untuk tempat mengurus suatu pekerjaan. Rumusan masalah yang akan di bahas dalam penelitian ini adalah sebagai berikut:

1. Bagaimana membuat sebuah sistem alert pada perkantoran yang mampu merespon laporan dengancepat

2. Bagaimana implementasi pendataan penanganan laporan yang masuk ke sistem dengan dibuatnyadatabase

DalamkomunikasiServerSecutritySystemdeng anaplikasiyangberadadigadget. Sistem ini memanfaatkan teknologi internet dalam komunikasinya lebih jelasnya adalah membuat sebuah website yang berisikan informasi yang berasal dari server yang kemudian diterima oleh aplikasi gadget . Web server sistem ini ditulis dengan bahasa pemrograman PHP dan databaseMySql.

Dengan memanfaatkan system login berupa password dan nomor telepon, dalam segi keamanan diharapkan website tersebut tidak bisa diakses selain pemilik kantor. Berbagaikeuntungan yang diperoleh jika menggunakan internet antara lain, standby 24 jam 
beroperasi sehingga sistem dapat dikontrol kapanpun, relatif lebih murah karena tidak perlu membangun jaringan intranet sendiri yang membutuhkan biaya lebih banyak

Adapun manfaat yang dapat diambil dari penelitian ini adalah :

1. Sebagaisaranauntuk mempelajari pengembangan aplikasi berbasismobile

2. Sebagai sarana belajar bagaimana mengatasi permasalahan pada sektor perkantoran dan pelayanannya dengan solusi-solusi yang berbasisIT

3. Untuk menjamin sampainya laporan para pegawai kantor secaracepat

4. Meningkatkan fasilitas perkantoran sehingga menjadi nilai tambah dalampelayanan

I.I AplikasiMobile

Aplikasi berasal dari kata application yang artinya pengunaan atau pemakaiaan.Secara istilah, aplikasi adalah program siap pakai yang dibuat untuk melaksanakan suatu fungsi bagi pengguna. Sedangkan mobile dapat diartikansebagai perpindahan yang mudah dari suatu tempat ke tempat yang lain, misalnya telepon mobile lainya. Aplikasi mobile awalnya ditunjukan untuk menunjang produktivitas seperti email, kalender dan kontak database, tetapi karena tingginya permintaan masyarakat akan aplikasi mobile akan menyebabkan aplikasi mobile mengarah ke fungsi yang lebih luas seperti mobile game, GPS atau layanan berbasis lokasi, pelayanan pelanggan maupun perbankan.

Agar dapat berjalan sesuai dengan fungsinya, aplikasi mobile memerlukan koneksi antara perangkat mobile dengan server penyedia data melalui koneksi yang disediakan oleh operator telekomunikasi melalui paket data yang disediakan.

Namun dalam pengembangannya ada beberapa anggapan yang salah mengenai mobile application dianggap lebih mudah:

1. Pengembangan aplikasi mobile dianggap lebihmudah:

Masyarakat merasa pengembangan aplikasi untuk perangkat mobile jauh lebih mudah, tapi kenyataannya lebih sulit.

2. Pengembangan aplikasi mobile lebih cepat:

Terdapat gagasan bahwa mengembangkan aplikasi perngakat mobile lebih cepat. Padahal sebenarnya,mungkintidaklebihcepatataulebihlamb atdibandingkanupayapengembangan aplikasi lain. Itu semua tergantung pada kerumitan aplikasi lain. Itu semua tergantung pada kerumitan aplikasi yang dikembangkan dan beberapa factor yanglain.

3. Pengembangan aplikasi mobile lebihmurah:

Aplikasi mobile maupun perangkat tidak semuanya harus perangkat mobile itu sendiri tidak murah jika anda membandingkan biaya PC Pocket atau tablet PC dengan computer desktop yang terhubung. Pada saat anda selesai membeli Pocket PC dan semua aksesorisnya, ia mungkin sama mahalnya dengan desktop (dan mungkin lebih mahal).

1.2 Kelebihan AplikasiMobile

Ada beberapa kelebihan dan keuntungan yang

dimiliki oleh aplikasimobile, diantaranya:

1. Meningkatkan kualitas kehidupanmanusia

Solusi untuk mobile dapat meningkatkan kualitas kehidupan dan pribadi seseorang. Seperti telepon seluler membantu para orangtua menghubungi dan mengontrol anak-anaknya.

2 Meningkatkan fleksibilitas dan aksebilitas parapekerja.

Denganaplikasimobile,parapekerjadapatdiberikanf leksibilitasdarilokasidanwaktuyang berbeda.

3. Meingkatkan keamanan parapekerja

Aplikasi mobile mampu menyediakan para pekerja dengan informasi situasi terkini (up to date) yang dapat meningkatkan keamanan para pekerja pada lokasi yang berbahaya.

4. Menigkatkan efesiensi dan produktivitaspekerjaan Aplikasi mobile juga membantu mengeliminasi redunsasi dalam aktivitas memasukan data. Contohnyasepertiseseorangyangmencatatnotesdal amrapat,orangtersebutharuskembali mengetik dan memasukan informasi ke dalamkomputernya.

5. Meningkatkan akurasi dan ketepatandata

Para pekerja yang menggunakan aplikasi mobile dapat menerima dan menyediakan informasi kepada sitem bisnis yang ada dengan waktu yang diinginkan.Selain itu angka kesalahan dapat dikurangi dalam aktivitas mengumpulkan dan melaporkan data.

6. Meningkatkan proses bisnis yang sudahada Para pekerja yang sudah mobile dapat meningkatkan sistem bibnis yang sudah ada. Perusahaan juga dapat meningkatkan dan mengeliminasi redunsi dalam aliran kerja.

7. Meningkatkan controlinventori Aplikasi mobile dapat membantu memonitor perlengkapan dan asset lainnya. 
8. Meningkatkan kepuasanpelanggan

Kepuasan pelanggan dapat ditingkatkan jika penjualan dan pelayanan menjadi efesien dan responsif. Dengan begitu pemasukan juga akan bertambah.

\section{INTERPRETASI}

Untuk mendapatkan data dan bahan dalam pembangunan sistem informasi ini penulis menggunakan beberapa metode diantaranya:

1. Metode Lapangan (FieldResearch)

Metode yang dilakukan dengan cara meninjau secara langsung di tempat penelitian guna mendapatkan data yang berhubungan dengan laporan akhir.

2. Metode Observasi (ObservationResearch)

Adalahsuatumetodeyangdilakukandengansuatupe ngamatanataukegiatanyangsistematis terhadap objek yang dituju secara langsung dengan meggunakan inderamata

3. MetodeWawancara

Adalah suatu metode yang dilakukan dengan cara tanya jawab oleh pewawancara secara pribadi bersama sumber yang ditanya. Dalam teknik wawancara ini penyusun berperan sebagai pewawancara, sedangkan sumbernya adalah pihak terkait yang berwenang.

4. Metode Literatur (LibraryResearch)

Metode yang dilakukan dengan membaca buku maupun sumber lainnya untuk mendapatkan data yang berhubungan dengan judul penelitian yang penulis ambil.

Sistem Keamanan digunakan untuk memberikan rasa bebas dari bahaya, tidak merasa takut, resah, atau gelisah terhadap barang berharga yang ditinggalkan.sistem keamanan dapat mengetahui emungkinan terjadinya pencurian terhadap barang berharga. Kantor adalah balai (gedung, rumah, ruang) tempat mengurus suatu pekejan.

\section{HASIL DANPEMBAHASAN}

TahapanPerancangansebuahsistemmemerlukan beberapaprosesyangharusdiselesaikan dalam rangka pembangunan sistem informasi tersebut.

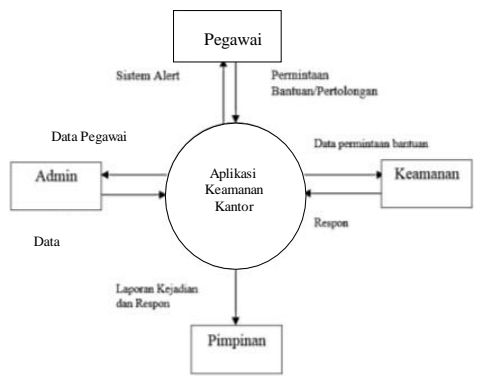

Gambar 1. Diagram Konteks

Diagramkonteksadalaharusdatayangberfungsiu ntukmenggambarkanketerkaitanaliranalirandataantarasistemdenganbagianbagianluar(kesatuanluar).Kesatuanluarinimerupakan sumber arus data atau tujuan data yang berhubungan dengan sistem informasi tersebut.Diagram konteks memberikan batasan yang jelas mengenai besaranbesaran entitas yang berada diluar sistemyangsedangdibuat,artinyadiagraminimengggam

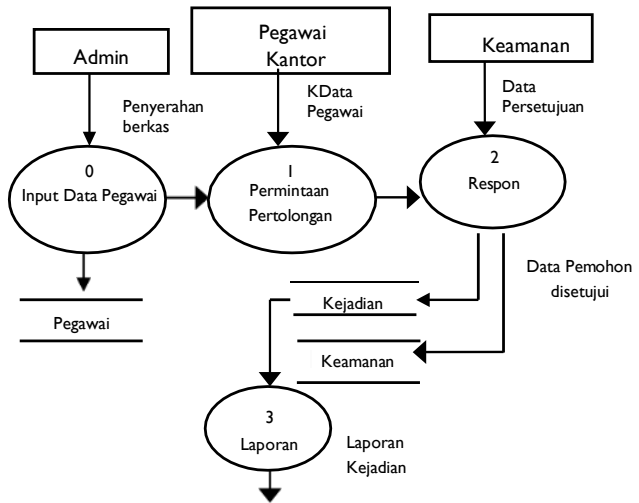

barkansecarajelasbatasan-batasandari sebuah sistem yang sedangdibuat.

Gambar 2. Data Flow Diagram Level 0

\subsection{RelasiTabel}

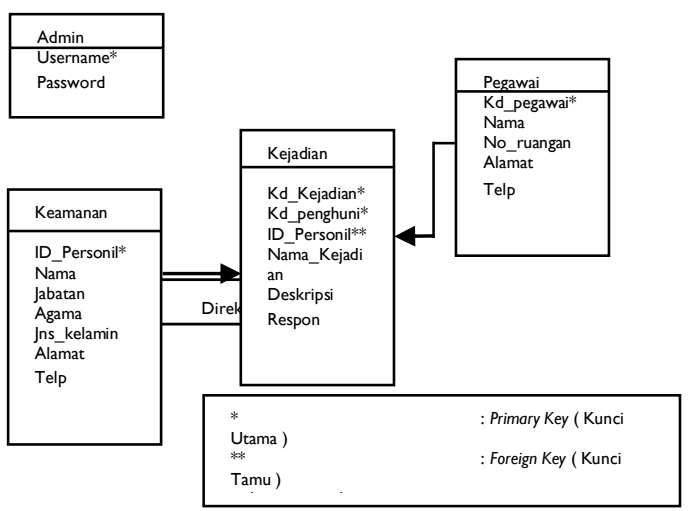

Gambar 3. Relasi Tabel

3.2 DesainForm

\subsubsection{Desain FormLogin}

Form login merupakan Form yang digunakan untuk membuka Form utama. Form ini 


\section{Jurnal Sains Komputer dan Teknologi Informasi Page e - issn : 2655-7460. Volume 3 No.1, November 2020 93 - 97}

dirancang untuk mengidentifikasi apakah user boleh masuk atau tidak, jika user tidakmemiliki namauser dan kata sandi yang cocok maka login ditolak atau tidak diijinkan dan akan ada peringatan bahwa nama user dan kata sandi tidak sesuai atau salah, serta untuk menghindari pihak yang tidak berkepentingan.

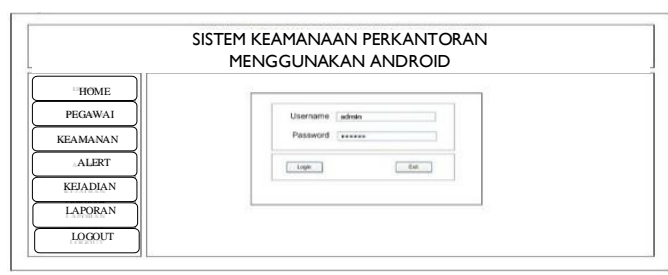

Gambar 4. Desain Form Login

3.2.2 Desain MenuUtama

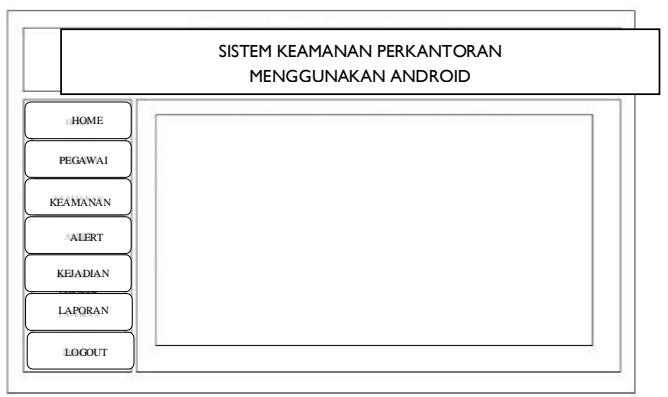

Gambar 5. Desain Form Menu Utama

\subsubsection{DesainPegawai}

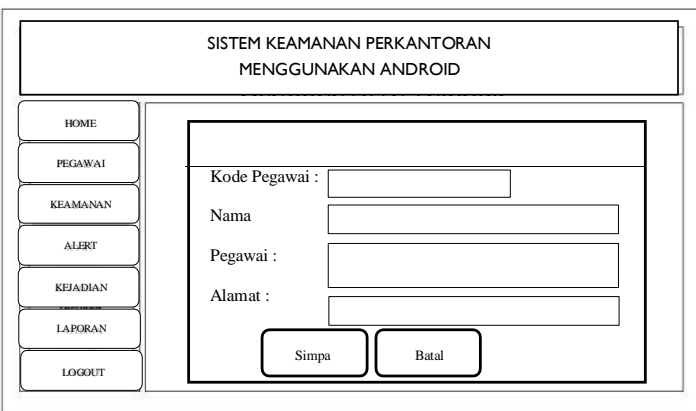

Gambar 5. Desain Form Pegawai Ruangan Kantor

\subsubsection{Desain Formkejadian}

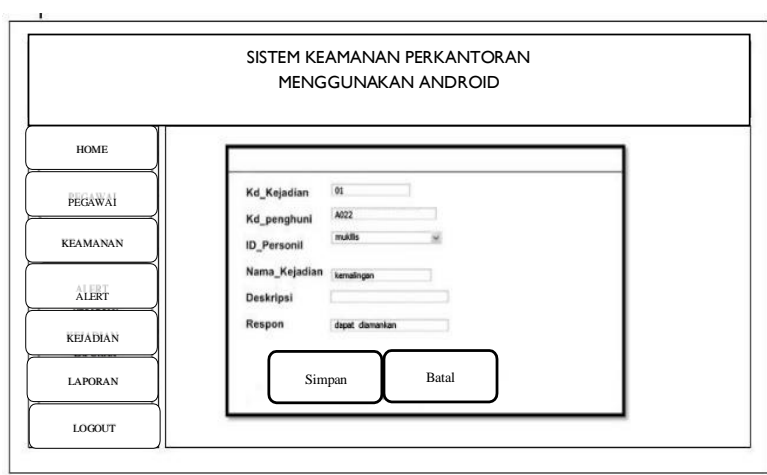

Gambar 6. Desain Form Kejadian Ruangan Kantor

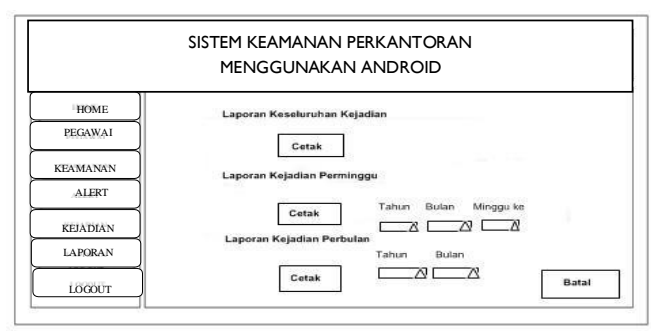

\subsubsection{Desain CetakLaporan}

Gambar 7. Desain Form Cetak Laporan

3.2.6 Desain TampilanAndroid

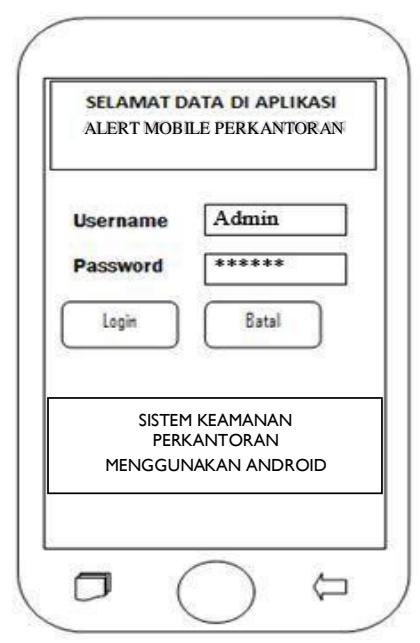

Gambar 8. Desain Login Aplikasi

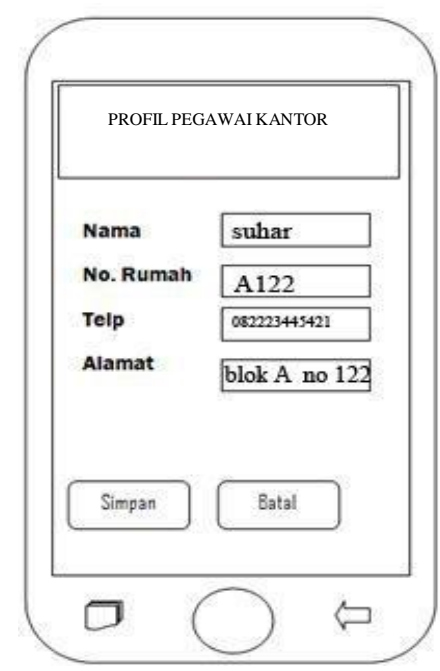

Gambar 9. Profil Pegawai Ruangan Kantor 


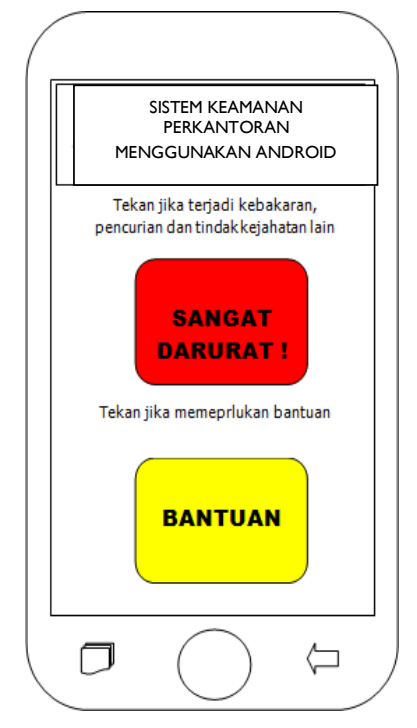

Gambar 10. Desain Menu Alert System Pegawai Ruangan Kantor

4. Simpulan

Adapun kesimpulan yang dapat diambil dari penelitian yang telah dilakukan penulis adalah sebagai berikut :

I. Dengan dikembangkannya sistem informasi alert sistem ini maka penghuni kantor pada sedikit

banyak lebih terbantu dalam hal pelaporan serta permintaanbantuan

2. Aplikasiinimampumengakomodasilaporanber kaitandengankeamanan,ketertibanserta pelayanan bagi para penghuniperkantoran

3. Setelah diterapkannya aplikasi ini maka perubahan yang dihasilkan antara lain dari kinerjamampumelakukanpengirimaninformasi danlaporandatasecaracepatdandinilai dari segi ekonominya mampu meningkatkan waktu respon para personil keamanan untuk mengatasi keluhan serta pertolongan yang diminta oleh para penghuniperkantoran.

\section{Saran}

Agar sistem ini berjalan dengan baik, ada beberapa hal yang perlu dilakukan dalam penggunaan serta pengembangannya, antara lain:

I. Sistem ini sebaiknya terus dikembangkan agar menjadi sistem yang lebih menunjang perkembangan teknologi dan kebutuhan akan sistem informasi yang lebih kompeten dimasa yang akandatang

2. Keamanan data sebaiknya dikelola secara benar dan berkesinambungan, serta perawatan (maintenance) hardware maupun software adalah sesuatu yang mutlak untukdilakukan.

\section{DAFTAR PUSTAKA}

Angger Binuko Paksi, (2014). Implementasi Web Service Untuk Perancangan Aplikasi Zoopedia Berbasis Android

Ayu Rizka Inayah,(2014). Aplikasi Pemesanan Menu Makanan Di Kantor Makan Berbasis Web Service Menggunakan Mobile Android

BandungHarianto, Kristanto. 1989. Konsep dan Perancangan Database, Andi Offset, Yogyakarta.

Fathansyah. 1999, Buku Teks Ilmu Komputer Basis Data, Informatika,

Jogianto. H. M, 2002. Analisa dan Desain Sistem Informasi. Andi Offset, Yogyakarta.

Karuniawan, Bagus. 2002. Sistem Informasi Manajemen. AndiYogyakarta. Yogyakarta.

Lusi Annisa L, (2015). Sistem Keamanan Rumah Menggunakan Glass Break Detector Berbasis Android

Mirza S.Kom, 2012. Sistem Informasi Akuntansi Penjualan Iklan dan Penerimaan Kas Rakyat Merdeka Group. Universitas Bina Nusantara.

HM, Jogyanto. (2009). Analisis \& Desain Sistem Informasi simbol yang digunakan Data Flow Diagram (DFD). Yogyakarta : Andi.

Kadir, Abdul. (2001). Dasar Pemrograman Android. Yogyakarta : Andi. Murya, Yosef. (2010). Peemrograman Android Balackbox. Jakarta : Jasakom.

Sutanta, Edhy. 2004, Sistem Basis Data, Graha Ilmu, Yogyakarta.

Sutabri, Tata. (2009). Analisis Sistem Informasi. Bandung : Alex Media Komputindo. 